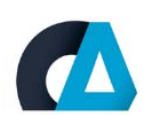

CENTROALGORITMI

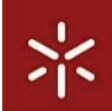

Universidade do Minho

Vítor Monteiro, José A. Afonso, Delfim Pedrosa, Júlio S. Martins, João L. Afonso

"Digital Control of a Novel Single-Phase Three-Port Bidirectional Converter to Interface Renewables and Electric Vehicles with the Power Grid"

CONTROLO Portuguese Conference on Automatic Control, Guimarães - Portugal, Sept. 2016.

http://link.springer.com/chapter/10.1007\%2F978-3-319-43671-5_56

ISBN: 978-3-319-43670-8

DOI 10.1007/978-3-319-43671-5_56

This material is posted here according with:

"The Author may self-archive an author-created version of his/her Contribution on his/her own website and/or in his/her institutional repository, including his/her final version. He/she may also deposit this version on his/her funder's or funder's designated repository at the funder's request or as a result of a legal obligation, provided it is not made publicly available until 12 months after official publication."

(C) 2014 SPRINGER 


\title{
Digital Control of a Novel Single-Phase Three-Port Bidirectional Converter to Interface Renewables and Electric Vehicles with the Power Grid
}

\author{
Vítor Monteiro $^{1}$, José A. Afonso ${ }^{2}$, Delfim Pedrosa ${ }^{1}$, Júlio S. Martins ${ }^{1}$, João L. Afonso ${ }^{1}$ \\ ${ }^{1}$ Centro Algoritmi - University of Minho - Guimarães, Portugal \\ \{vitor.monteiro, delfim.pedrosa,julio.martins, joao.l.afonso\} \\ @algoritmi.uminho.pt \\ ${ }^{2}$ CMEMS-UMinho R\&D Center, University of Minho - Guimarães, Portugal \\ jose.afonsoddei. uminho.pt
}

\begin{abstract}
This paper presents the digital control of a novel single-phase three-port bidirectional (STB) converter used to interface renewables from solar photovoltaic (PV) panels and electric vehicles (EVs) with the power grid. Using an appropriated power theory, the STB converter can be used to exchange energy between the PVs, the EVs and the power grid in four distinct modes: (1) The $\mathrm{EV}$ receives energy from the power grid $(\mathrm{G} 2 \mathrm{~V}$ - grid-to-vehicle operation mode) or delivers energy to the power grid (V2G - vehicle-to-grid operation mode); (2) All the energy produced by the PV panels is delivery to the power grid; (3) All the energy produced by the PV panels is delivery to the EV; (4) The EV can receive energy simultaneously from the PV panels and from the power grid $(\mathrm{G} 2 \mathrm{~V})$. The currents of the power grid, PV panels and EV are controlled through independent predictive current control strategies, which ensure good power quality levels. This paper presents the architecture of the proposed STB converter and the detailed explanation of the digital implementation of the control algorithms, namely, the power theory and the predictive current control strategies. The control algorithms were validated through computational simulations and experimental results.
\end{abstract}

Keywords: Digital Control; Predictive Current Control; Three-Port Converter; Renewables; Electric Vehicle; Power Grid.

\section{Introduction}

Nowadays, the electric vehicle (EV) is considered the main alternative to reduce the energy consumption associated to the transport sector $[1,2]$. Consequently, with the $\mathrm{EV}$ introduction in power grids, new opportunities emerge for the EV users and for the power grids towards smart grids $[3,4,5,6]$. Some of these opportunities are related with the grid-to-vehicle $(\mathrm{G} 2 \mathrm{~V})$ and the vehicle-to-grid (V2G) operation modes. In this context, a flexible infrastructure for dynamic power control of EV battery chargers is presented in [7]. Taking into account the advances in microgeneration, 

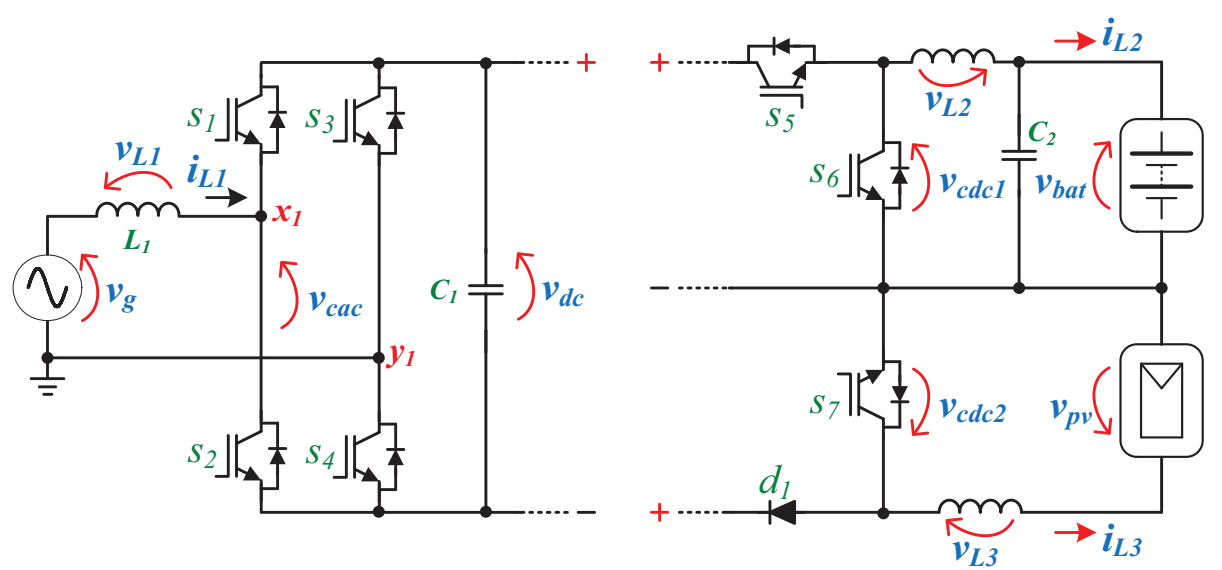

Fig. 1. Proposed single-phase three-port bidirectional (STB) converter.

also emerge new opportunities to integrate the EV with renewables. For instance, a study about the utility of the EV to help to stabilize the power grid voltage with a large-scale renewable energy introduction is presented in [8], an energy management strategy to integrate EVs and renewables is presented in [9], and an optimal dispatch of EVs with renewables (wind power) is presented in [10]. Moreover, the integration of EVs with renewables will allow mitigating the greenhouse gas emissions $[11,12]$. Although there are collaborative control strategies to integrate EVs and renewables in power grids, these systems are physically independents.

This paper proposes a novel single-phase three-port bidirectional (STB) converter to interface renewables from solar photovoltaic (PV) panels and the EVs in power grids. Fig. 1 presents the proposed STB converter. As it can be seen, it is composed by an ac-dc stage to interface the power grid, a dc-dc stage to interface the EV, and other dc-dc stage to interface the PV panels. Comparing with the traditional solutions, the main advantage of the proposed solution is the possibility to charge the EV batteries from the PV panels without the ac-dc stage. The three stages are connected to the same dc-link, which is controlled by the ac-dc stage, and the current of each stage is controlled through individual predictive current controllers.

\section{Proposed Single-Phase Three-Port Bidirectional Converter}

This section presents the proposed STB converter. As shown in Fig. 1, the ac-dc stage is a full-bridge voltage-source converter, which is used to control the dc-link voltage and to control the amplitude and phase of the power grid current. When the STB receives energy from the power grid, the grid current is in phase with the power grid voltage. When the STB converter delivers energy to the power grid, the grid current is in phase opposition with the power grid voltage. The voltage produced by the converter $\left(v_{c a c}\right)$, i.e., the voltage between the points $x_{1}$ and $y_{1}$ identified in Fig. 1, can assume three distinct values. When the power grid voltage is positive, the voltage $v_{c a c}$ can be $+v_{d c}$ or 0 . When the IGBTs $s_{1}$ and $s_{4}$ are on and the IGBTs $s_{2}$ and $s_{3}$ are off, the voltage $v_{c a c}$ is $+v_{d c}$. When the IGBTs $s_{1}$ and $s_{3}$ are on and the IGBTs $s_{2}$ and $s_{4}$ are off, 
the voltage $v_{c a c}$ is 0 . On the other hand, when the power grid voltage is negative, the voltage $v_{c a c}$ can be $-v_{d c}$ or 0 . When the IGBTs $s_{2}$ and $s_{3}$ are on and the IGBTs $s_{1}$ and $s_{4}$ are off, the voltage $v_{c a c}$ is $-v_{d c}$. When the IGBTs $s_{2}$ and $s_{4}$ are on and the IGBTs $s_{l}$ and $s_{3}$ are off, the voltage $v_{c a c}$ is 0 .

As shown in Fig. 1, both dc-dc stages are composed by half-bridge voltage-source converters. The dc-dc stage used o interface the EV can operate in bidirectional mode. During the EV batteries charging process ( $\mathrm{G} 2 \mathrm{~V})$ it operates as a buck-type converter, i.e., the IGBT $s_{6}$ is always off. When the IGBT $s_{5}$ is on, the voltage produced by this converter, $v_{c d c l}$ (i.e., the voltage between the points $x_{2}$ and $y_{2}$ identified in Fig. 1), is $v_{d c}$, and when the IGBT $s_{5}$ is off the voltage $v_{c d c l}$ is 0 . During the EV batteries discharging process $(\mathrm{V} 2 \mathrm{G})$ it operates as a boost-type converter, i.e., the IGBT $s_{5}$ is always off. When the IGBT $s_{6}$ is on, the voltage produced by this converter $\left(v_{c d c l}\right)$ is 0 and when the IGBT $s_{6}$ is off the voltage $v_{c d c l}$ is $v_{d c}$. On the other hand, the dc-dc stage used to interface the PV panels operates in unidirectional mode. When the IGBT $s_{7}$ is on, the voltage produced by this converter, $v_{c d c 2}$ (i.e., the voltage between the points $x_{3}$ and $y_{3}$ identified in Fig. 1), is 0 , and when the IGBT $s_{7}$ is off the voltage $v_{c d c 2}$ is $v_{d c}$.

\section{Digital Control Algorithm Analysis}

This section presents the detailed analysis of the digital control algorithm for both ac-dc and dc-dc stages, which is implemented in the digital signal processor (DSP) TMS320F28335 from Texas Instruments. Fig. 2 shows the digital control algorithm of the STB converter and Fig. 3 shows the time required to perform the main tasks of the digital control algorithm.

\subsection{Power Theory}

The power theory consists in determining the operation power of the STB converter. From the point of view of the power grid, this operation power is defined by:

$$
P_{G}=V_{G} I_{G},
$$

where $V_{G}$ is the rms value of the power grid voltage and $I_{G}$ is the rms value of the grid current. Taking into account that the STB converter should operate with unitary power factor, the grid current should be in phase with the power grid voltage, therefore, it can be established that:

$$
i_{g}=G_{G} v_{g},
$$

where $G_{G}$ defines the STB converter as an conductance from the point of view of the power grid. Rearranging (1) it can be established that:

$$
P_{G}=G_{G} V_{G}^{2} .
$$

Merging (2) and (3), the operation power can be defined by:

$$
P_{G}=\frac{i_{g}}{v_{g}} V_{G}{ }^{2} .
$$




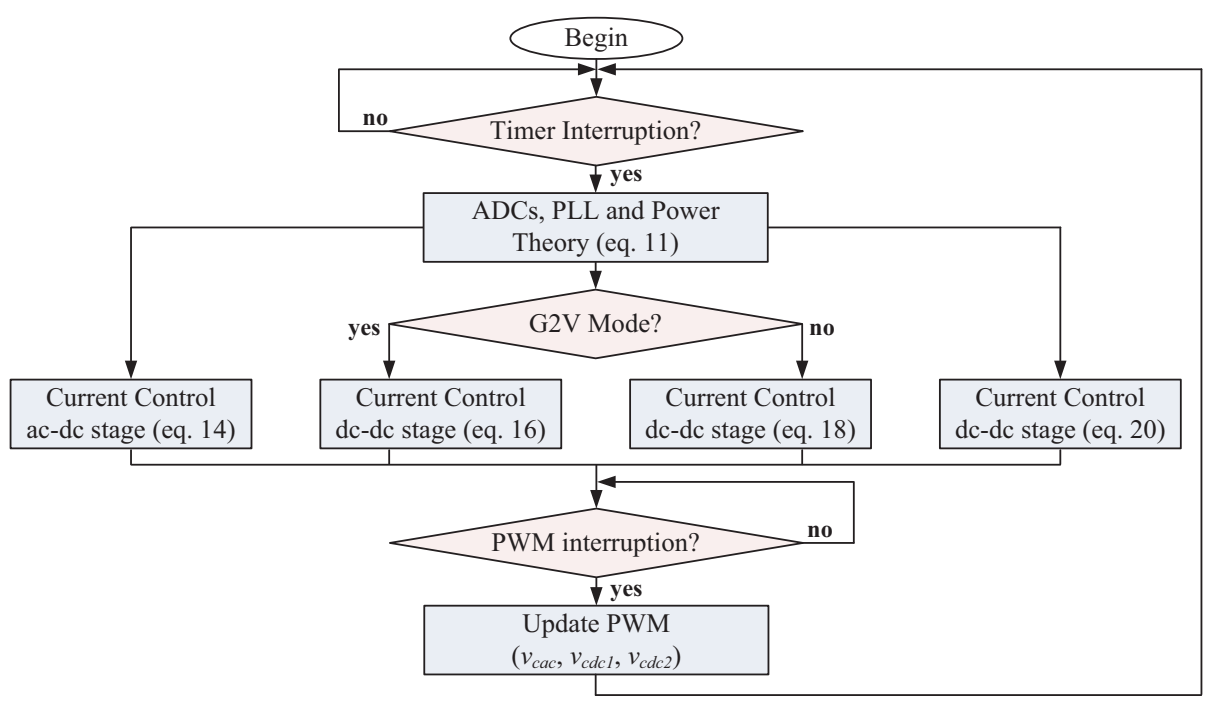

Fig. 2. Control algorithm of the proposed single-phase three-port bidirectional (STB) converter.

\begin{tabular}{|c|c|c|c|c|c|}
\hline \multirow[b]{2}{*}{$\mathrm{ADCs}$} & \multirow[b]{2}{*}{ PLL } & \multirow[b]{2}{*}{ Power Theory } & \multicolumn{3}{|c|}{ Predictive Current Control } \\
\hline & & & (ac-dc stage) & (dc-dc stage) & (dc-dc stage) \\
\hline $690 \mathrm{~ns}$ & $820 \mathrm{~ns}$ & $2687 \mathrm{~ns}$ & $1707 \mathrm{~ns}$ & $1707 \mathrm{~ns}$ & $1707 \mathrm{~ns}$ \\
\hline
\end{tabular}

Fig. 3. Time required to perform the main tasks of the digital control algorithm.

On the other hand, from the point of view of the dc-link, the operation power is defined by the power to maintain the dc-link voltage regulated $\left(P_{D C}\right)$, by the power of the EV batteries $\left(P_{B A T}\right)$, and by the power of the PV panels $\left(P_{P V}\right)$, according to:

$$
P_{G}-P_{D C}-P_{E V}-P_{P V}=0 \text {. }
$$

Merging (4) and (5), the final control law that defines the operation power of the STB converter is established by:

$$
\frac{i_{g}}{v_{g}} V_{G}{ }^{2}-P_{D C}-v_{b a t} i_{b a t}-v_{p v} i_{p v}=0,
$$

where $P_{D C}$ is obtained from a PI controller, whose digital implementation is obtained from:

$$
\begin{gathered}
m_{P}[k]=k_{p}\left(v_{d c}{ }^{*}[k]-\overline{v_{d c}}[k]\right), \\
m_{I}[k]=k_{i} f_{S}\left(v_{d c}{ }^{*}[k]-\overline{v_{d c}}[k]\right)+m_{I}[k-1], \\
P_{D C}[k]=m_{P}[k]+m_{I}[k] .
\end{gathered}
$$

$\overline{v_{d c}}$ represents the average value of the dc-link voltage during one cycle of the power grid voltage $(50 \mathrm{~Hz})$. It is used $\overline{v_{d c}}$ instead of $v_{d c}$ in order to avoid introducing 
the dc-link voltage oscillation into the control. The discrete implementation is obtained according to:

$$
\overline{v_{d c}[n]}=\frac{1}{M} \sum_{n=1}^{T} v_{d c}[n] .
$$

Using a sampling frequency of $20 \mathrm{kHz}, M$ corresponds to 400 samples. The digital implementation of the final control law is defined by:

$$
\frac{i_{g}[k]}{v_{g}[k]} V_{G}{ }^{2}[k]-m_{P}[k]+m_{I}[k]-v_{b a t}[k] i_{b a t}[k]-v_{p v}[k] i_{p v}[k]=0 \text {. }
$$

Nowadays, due to the nonlinear loads and the line impedance, the power grid voltage can have harmonic content. Therefore, instead of use the power grid voltage, it is used a phase-locked loop (PLL) algorithm, where the output signal is proportional only to the fundamental component $(50 \mathrm{~Hz})$ of the power grid voltage.

\subsection{Predictive Current Control}

The grid current $\left(i_{g}\right)$, the EV battery charging current $\left(i_{\text {bat }}\right)$, and the PV panels current are controlled independently by predictive current controllers. The current reference for the ac-dc stage is defined by equation (11), the current reference for the EV batteries charging is defined by the battery management system (BMS), and the current reference for the PV panels is obtained from a maximum power point tracking (MPPT) algorithm. It is important to note that the BMS and the MPPT are not explained in detail, since they are out of the scope of this paper.

For the ac-dc stage, from Fig. 1, analyzing the voltages between the power grid and the STB converter, it can be established that:

$$
v_{g}-v_{L 1}-v_{c a c 1}=0,
$$

where $v_{g}, v_{L I}$ and $v_{c a c}$ are, respectively, the instantaneous values of the power grid voltage, the inductance voltage, and the voltage between the points $x_{l}$ and $y_{1}$. Substituting the inductance voltage, it can be established that:

$$
v_{g}-L_{1} \frac{d i_{L 1}}{d t}-v_{c a c 1}=0,
$$

where the current in the inductance $\left(i_{L I}\right)$ is the power grid current $\left(i_{g}\right)$. Using the forward Euler method, equation (13) can be rewritten in terms of discrete samples as:

$$
v_{g}[k]-\frac{L_{1}}{T_{s}}\left(i_{g}[k+1]-i_{g}[k]\right)-v_{c a c 1}[k]=0,
$$

where the grid current in the instant $[k+l]$ should be equal to the current reference in the instant $[k]$. The current reference is obtained from (11). During each period $[k, k+1]$ the voltage $v_{c a c}$ is updated and compared with a unipolar pulse-width modulator (PWM) output in order to obtain the IGBTs gate pulse patterns, i.e., to define the state of the ac-dc stage. Considering that it is used a unipolar PWM, it is also used a voltage $\left(-v_{c a c}\right)$ symmetrical in relation to the horizontal middle of the PWM carrier. 
For the dc-dc stage used to interface the VE, the current is analyzed for the G2V and V2G operation modes. During the G2V operation mode, from Fig. 1, analyzing the voltages between the STB converter and the dc-dc stage, it can be established that:

$$
v_{\text {bat }}+v_{L 2}-v_{c d c 1}=0,
$$

where $v_{b a t}, v_{L 2}$ and $v_{c d c l}$ are, respectively, the instantaneous values of the EV batteries voltage, the inductance voltage, and the voltage between the points $x_{2}$ and $y_{2}$. Knowing that the current in the inductance $\left(i_{L 2}\right)$ is the EV batteries current $\left(i_{b a t}\right)$, substituting the inductance voltage and using the forward Euler method, the discrete implementation of (15) results in:

$$
v_{b a t}[k]+\frac{L_{2}}{T_{s}}\left(i_{b a t}[k+1]-i_{b a t}[k]\right)-v_{c d c 1}[k]=0 .
$$

where the EV batteries current in the instant $[k+1]$ should be equal to the current reference in the instant $[k]$. On the other hand, during the V2G operation mode, from Fig. 1, analyzing the voltages between the STB converter and the EV batteries, it can be established that:

$$
v_{\text {bat }}-v_{L 2}-v_{c d c 1}=0,
$$

where the digital implementation results in:

$$
v_{\text {bat }}[k]-\frac{L_{2}}{T_{S}}\left(i_{\text {bat }}[k+1]-i_{\text {bat }}[k]\right)-v_{c d c 1}[k]=0 .
$$

Taking into account that the current will follow in the opposite direction, in the digital implementation the current $i_{\text {bat }}[k]$ represented in (18) should be $-i_{\text {bat }}[k]$. For both situations ( $\mathrm{G} 2 \mathrm{~V}$ and $\mathrm{V} 2 \mathrm{G})$, the voltage $v_{c d c l}$ is actualized and compared, during each period $[k, k+1]$, with a PWM, in order to obtain the IGBTs gate pulse patterns of the dc-dc stage used to interface the EV batteries.

For the dc-dc stage used to interface the PV panels, from Fig. 1, analyzing the voltages between the STB converter and the PV panels, it can be established that:

$$
v_{p v}-v_{L 3}-v_{c d c 2}=0
$$

where the digital implementation results in:

$$
v_{p v}[k]-\frac{L_{3}}{T_{s}}\left(i_{p v}[k+1]-i_{p v}[k]\right)-v_{c d c 2}[k]=0 .
$$

Also, for this stage, the voltage $v_{c d c 2}$ is updated and compared, during each period $[k, k+1]$, with a PWM, in order to obtain the IGBT gate pulse patterns of the dc-dc stage used to interface the PV panels.

\section{$4 \quad$ Simulations and Experimental Results}

This section presents the main simulations and experimental results obtained to validate the power theory and the predictive current control strategies of the proposed STB converter. Fig. 4 shows some simulations results of the STB converter. Fig. 4(a) shows the grid current $\left(i_{g}\right)$, as well as the digital grid current $\left(i_{g d}\right)$ and the digital cur- 

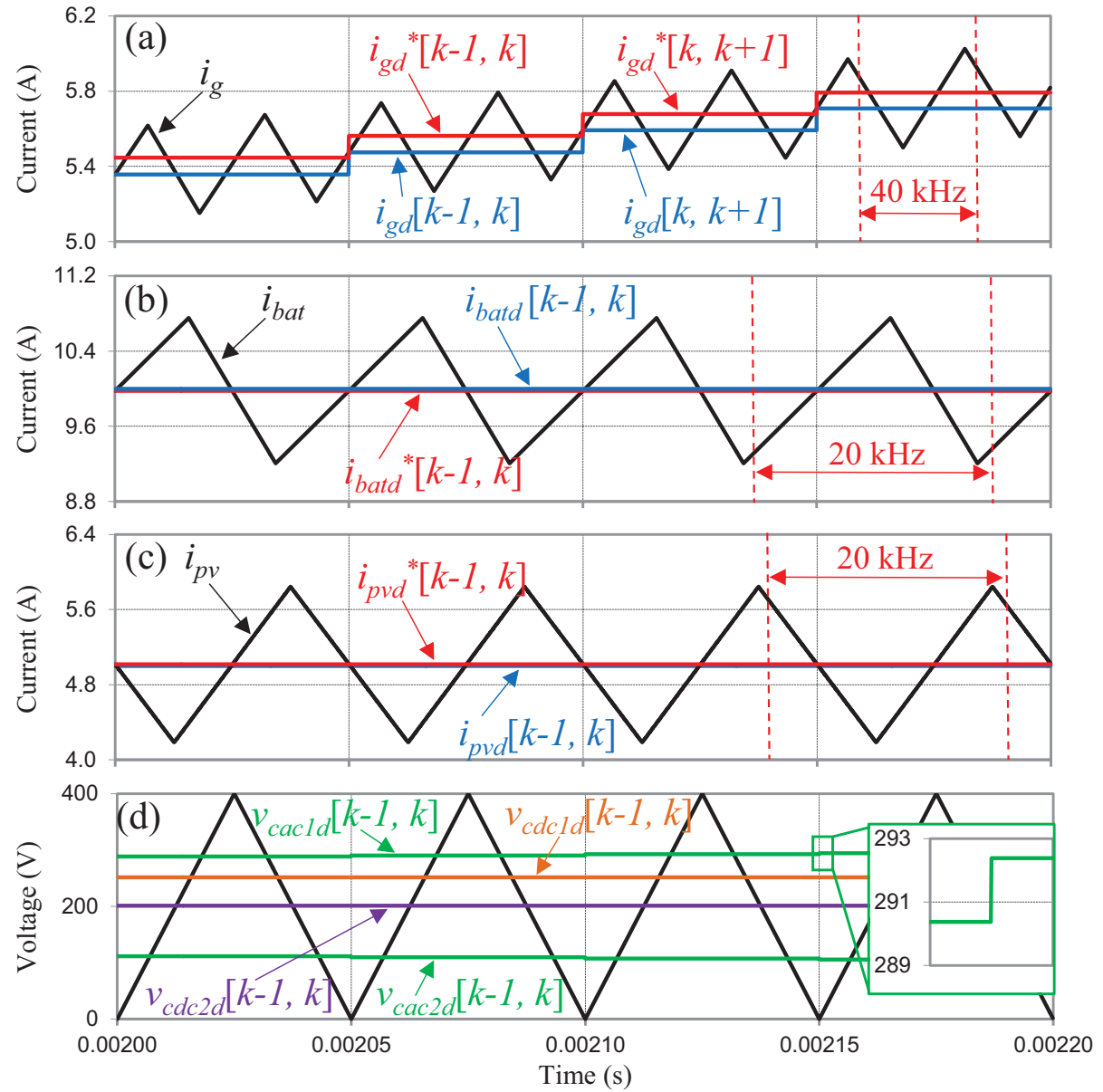

Fig. 4. Simulation results of the STB converter: (a) Grid current $\left(i_{g}\right)$, digital grid current $\left(i_{g d}\right)$, and its reference $\left(i_{g d} *\right)$; (b) EV batteries current $\left(i_{b a t}\right)$, digital EV batteries current $\left(i_{\text {batd }}\right)$ and its reference $\left(i_{b a t d}{ }^{*}\right)$; (c) PV panels current $\left(i_{p v}\right)$, digital PV panels current $\left(i_{p v d}\right)$ and its reference $\left(i_{p v d^{*}}\right)$; (d) PWM carrier and digital voltages produced by the ac-dc stage $\left(v_{\text {cacld }}[k-1, k]\right.$ and $\left.v_{c a c 2 d}[k-1, k]\right)$ and by both dc-dc stages $\left(v_{c d c l d}[k-1, k]\right.$ and $\left.v_{c d c l d}[k-1, k]\right)$.

rent reference $\left(i_{g d}{ }^{*}\right)$. As it can be seen, due to the unipolar PWM the resulting frequency of the grid current is $40 \mathrm{kHz}$ and the current $i_{g d}[k, k+1]$ is equal to the current reference $i_{g d} *[k-1, k]$. Fig. 4 (b) shows the EV batteries current $\left(i_{b a t}\right)$, as well as the digital EV batteries current $\left(i_{\text {batd }}\right)$ and its reference $\left(i_{\text {batd }} *\right)$. It is possible to observe that the switching frequency is $20 \mathrm{kHz}$ and the current $i_{\text {batd }}[k-1, k]$ is practically equal to the current reference $i_{\text {batd }} *[k-1, k]$. Fig. 4(c) shows the PV panels current $\left(i_{p v}\right)$, as well as the digital PV panels current $\left(i_{p v d}\right)$ and its reference $\left(i_{p v d} *\right)$. Also in this figure, it is possible to observe that the switching frequency is $20 \mathrm{kHz}$ and the current $i_{p v d}[k-$ $1, k]$ is practically equal to the current reference $i_{p v d} *[k-1, k]$. Fig. 4(d) shows the PWM carrier and the digital voltages produced by the ac-dc stage $\left(v_{\text {cacld }}[k-1, k]\right.$ and 

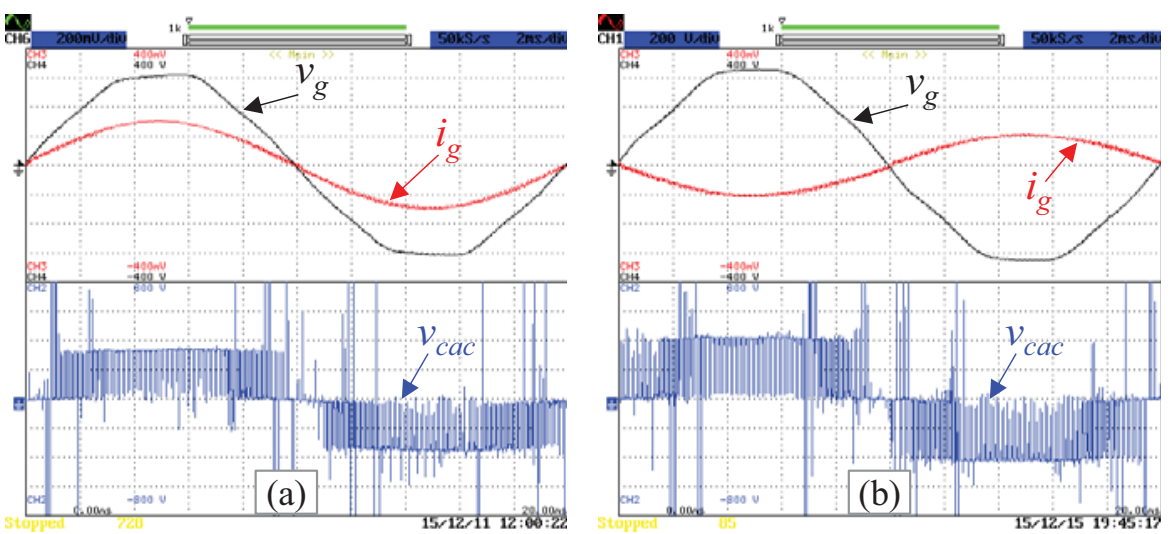

Fig. 5. Experimental results of the power grid voltage $\left(v_{g}\right)$, grid current $\left(i_{g}\right)$, and voltage produced by the converter $\left(v_{c a c}\right)$ : (a) When the STB receives energy from the power grid; (b) When the STB delivers energy to the power grid.
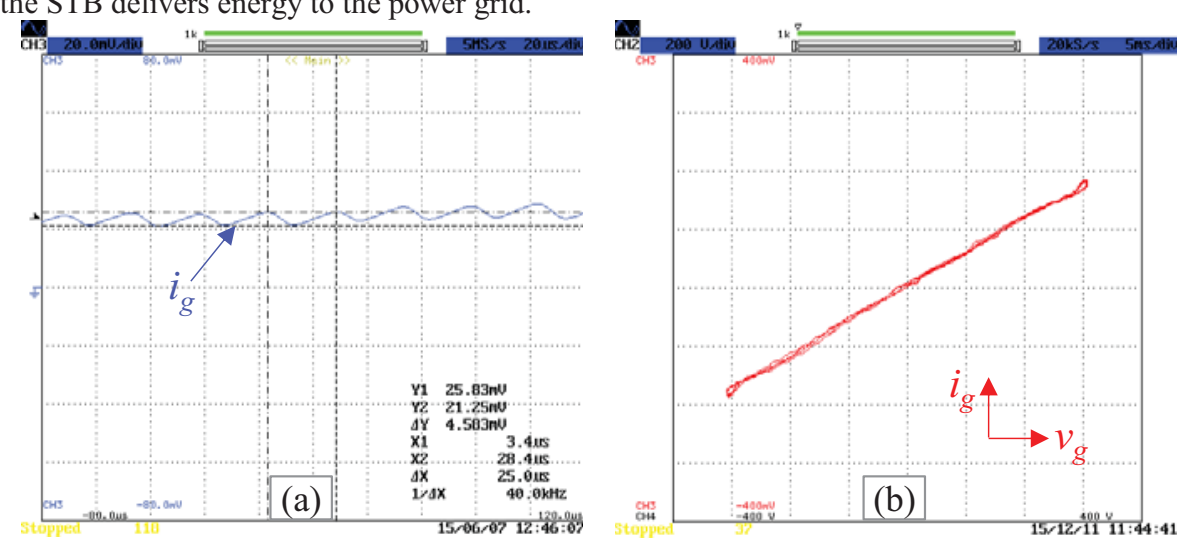

Fig. 6. Experimental results: (a) Detail of the grid current $\left(i_{g}\right)$; (b) Relation between the grid current and the power grid voltage (X-Y mode).

$\left.v_{\text {cac2d }}[k-1, k]\right)$ and by both dc-dc stages $\left(v_{\text {cdcld }}[k-1, k]\right.$ and $\left.v_{\text {cdcld }}[k-1, k]\right)$. As expected, the voltages $v_{\text {cacld }}[k-1, k]$ and $v_{\text {cac } 2}[k-1, k]$ are symmetrical in relation to the horizontal middle of the PWM carrier. Fig. 5(a) shows the power grid voltage $\left(v_{g}\right)$, the grid current $\left(i_{g}\right)$, and the voltage produced by the converter $\left(v_{c a c}\right)$ when the STB converter receives energy from the power grid. This experimental result was obtained with the dc-link voltage controlled for $370 \mathrm{~V}$ and for an operating power of $2.5 \mathrm{~kW}$. Fig. 5(b) shows the same variables, but when the STB converter delivers energy to the power grid. This experimental result was obtained with the dc-link voltage controlled for $410 \mathrm{~V}$ and for an operating power of $2 \mathrm{~kW}$. As it can be observed, in both cases, the grid current is sinusoidal and the voltage produced by the STB converter can assume three distinct values: $-v_{d c}, 0$ or $+v_{d c}$. Fig. $6\left(\right.$ a) shows the grid current $\left(i_{g}\right)$ in detail in order to illustrate the current ripple $(0.5 \mathrm{~A})$ and the switching frequency $(20 \mathrm{kHz})$. Fig. 6(b) shows the grid current in function of the power grid voltage. The relation is almost purely linear due to the power theory and the predictive current control. 

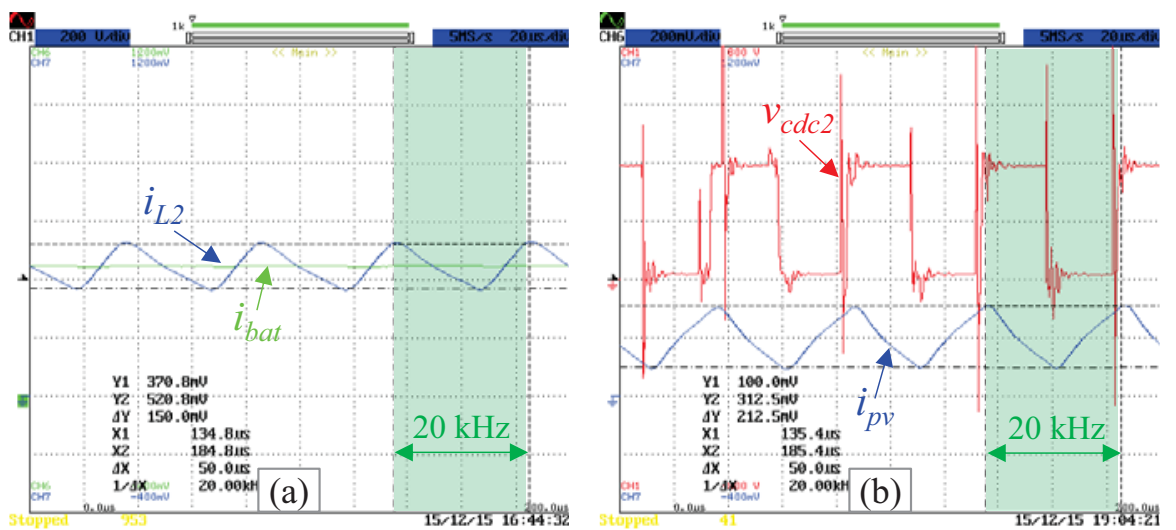

Fig. 7. Experimental results: (a) EV batteries current (ibat $)$ and current in the inductance $L_{2}\left(i_{L 2}\right)$; (b) PV panels current $\left(i_{p v}\right)$ and voltage produced by the converter $\left(v_{c d c 2}\right)$.

Fig. 7 shows the experimental results when the power produced by the PV panels is used to charge the EV batteries, i.e., the ac-dc stage is used only to regulate the dc-link voltage. Fig. 7(a) shows the EV batteries current $\left(i_{\text {bat }}\right)$ and the current in the inductance $L_{2}\left(i_{L 2}\right)$. During this operation mode the IGBT $s_{6}$ is always off. When the IGBT $s_{5}$ is on the voltage produced by the converter is $v_{d c}$ and the inductance stores energy. When the IGBT $s_{5}$ is off the voltage produced by the converter is 0 and the inductance delivers energy. Fig. 7(b) shows the PV panels current $\left(i_{p v}\right)$ and the voltage produced the converter $\left(v_{c d c 2}\right)$. When the IGBT $s_{7}$ is on, the voltage produced by the converter is 0 and the inductance stores energy. When the IGBT $s_{7}$ is off, the voltage produced by the converter is $v_{d c}$ and the inductance delivers energy.

\section{Conclusions}

This paper presents the digital control of a novel single-phase three-port bidirectional (STB) converter. This converter is used to interface renewables from photovoltaic (PV) panels and electric vehicles (EV) with the power grid taking into account power quality issues. The principle of operation of the proposed STB converter is explained in detail. Also, the digital control algorithms are explained in detail, including the power theory and the predictive current control strategies to control the grid current, the EV batteries charging current, and the PV panels current. The proposed STB converter, as well as the digital control algorithm, were validated through simulations and experimental results. For the ac-dc stage, the experimental results show that the grid current is sinusoidal during the G2V and V2G operation modes, and that the voltage produced by the STB converter can assume three distinct values: $+v_{d c}, 0,-v_{d c}$. Therefore, it was possible to confirm the proper operation of the predictive current control and the dc-link voltage control strategy. For both dc-dc stages, the experimental results show the proper operation of the predictive current control for controlling the PV panels current (operation as boost type converter) and the EV batteries current (operation as buck type converter). 


\section{Acknowledgements}

This work is supported by FCT with the reference project UID/EEA/04436/2013, by FEDER funds through the COMPETE 2020 - Programa Operacional Competitividade e Internacionalização (POCI) with the reference project POCI-01-0145-FEDER006941. The PhD student Vítor Monteiro was supported by the doctoral scholarship SFRH/BD/80155/2011 granted by the FCT agency.

\section{References}

1. Dyke, K. J., Schofield, N., Barnes, M.: The Impact of Transport Electrification on Electrical Networks. In IEEE Transactions on Industrial Electronics, vol.57, no.12, pp.39173926, (2010).

2. Rajashekara, K.: Present Status and Future Trends in Electric Vehicle Propulsion Technologies. In IEEE Journal Emerging and Selected Topics in Power Electronics, vol.1, no.1, pp.3-10, (2013).

3. Monteiro, V., Pinto, J. G., Afonso, J. L.: Operation Modes for the Electric Vehicle in Smart Grids and Smart Homes: Present and Proposed Modes. In IEEE Transactions on Vehicular Technology, vol.65, no.3, pp.1007-1020, Mar. 2016.

4. Gungor, V. C., Sahin, D., Kocak, T., Ergut, S., Buccella, C., Cecati, C., Hancke, G. P.: Smart Grid and Smart Homes - Key Players and Pilot Projects. In IEEE Industrial Electronics Magazine, vol.6, pp.18-34, (2012).

5. Ferreira, J. C., Monteiro, V., Afonso, J. L.: Vehicle-to-Anything Application (V2Anything App) for Electric Vehicles. In IEEE Transactions on Industrial Informatics, vol.10, no.3, pp.1927-1937, (2014).

6. Monteiro, V., Exposto, B., Ferreira, J. C., Afonso, J. L.: Improved Vehicle-to-Home (iV2H) Operation Mode: Experimental Analysis of the Electric Vehicle as Off-Line UPS. In IEEE Transactions on Smart Grid, 2016.

7. Monteiro, V., Carmo, J. P., Pinto, J. G., Afonso, J. L.: A Flexible Infrastructure for Dynamic Power Control of Electric Vehicle Battery Chargers. In IEEE Transactions on Vehicular Technology, (2015).

8. Kempton, W., Tomic, J.: Vehicle-to-Grid Power Implementation: From Stabilizing the Grid to Supporting Large-Scale Renewable Energy. In ELSEVIER Journal of Power Sources, vol.144, pp.280-294, (2015).

9. Gao, S., Chau, K. T., Liu, C., Wu, D., Chan, C. C.: Integrated Energy Management of Plug-in Electric Vehicles in Power Grid With Renewables. In IEEE Transactions on Vehicular Technology, vol.63, no.7, pp.3019-3027, (2014).

10. Zhao, J. H., Wen, F., Dong, Z. Y., Xue, Y., Wong, K. P.: Optimal Dispatch of Electric Vehicles and Wind Power Using Enhanced Particle Swarm Optimization. In IEEE Transactions on Industrial Informatics, vol.8, no.4, pp.889-899, (2012).

11. "Environmental Assessment of Plug-In Hybrid Electric Vehicles". Electric Power Research Institute and Natural Resources Defense Council, vol.1: Nationwide Greenhouse Gas Emissions, (2007).

12. Saber, A. Y., Venayagamoorthy, G. K.: Plug-in Vehicles and Renewable Energy Sources for Cost and Emission Reductions. In IEEE Transactions on Industrial Electronics, vol.58, no.4, pp.1229-1238, (2011). 